\title{
Impact of Reentrant Ferroelectric-tetragonal Phase on the Structure, Spectral, Electric, Magnetic and Magnetoelectric Properties of $\mathrm{Gd}^{3+}-\mathrm{Fe}^{3+} \mathrm{Co}$ substituted $\mathrm{BaTiO}_{3}$ Ceramics
}

\section{Esther Rubavathi P}

Manonmaniam Sundaranar University

Dhayanidhi D

National Institute of Technology Tiruchirappalli

Giridharan N.V.

National Institute of Technology Tiruchirappalli

Rahul M.T.

Catholicate college

Nandakumar Kalarikkal

Mahatma Gandhi University

Sundarakannan B ( $\square$ sundarakannan@msuniv.ac.in )

Manonmaniam Sundaranar University

\section{Research Article}

Keywords: Gd3+-Fe3+, Rietveld refinement, SAED, Ferromagnetism, Magnetoelectric

Posted Date: August 6th, 2021

DOl: https://doi.org/10.21203/rs.3.rs-775883/v1

License: (c) (1) This work is licensed under a Creative Commons Attribution 4.0 International License.

Read Full License 


\section{Abstract}

The tetragonal reentrant phase conversion $(\mathrm{P} 4 \mathrm{~mm})$ is obtained from the phase coexistence of the tetragonal and the non-polar hexagonal phases $\left(\mathrm{PG}_{3} / \mathrm{mmc}\right)$ as a structural effect due to $\mathrm{Gd}$ substitution in $\mathrm{Ba}_{1-y} \mathrm{Gd}_{\mathrm{y}} \mathrm{Ti}_{1-\mathrm{x}} \mathrm{Fe}_{\mathrm{x}} \mathrm{O}_{3}(\mathrm{x}=0.05 ; \mathrm{y}=0.005,0.01$ and 0.015$)$ ceramics. The diffraction spots in the SAED patterns and the d-spacing of the HREM lattice fringes mainly evidence the coexistence of the structural phase. Rietveld refinement offers the bond length and the other structural data. Ti presents itself as $\mathrm{Ti}^{3+}$ and $\mathrm{Ti}^{4+}$ whereas Fe presents as $\mathrm{Fe}^{2+}$ and $\mathrm{Fe}^{3+}$, revealed by the XPS spectra. The octahedra partly change to pentahedral due to the creation of the charge compensating the oxygen vacancies and therefore the conversion from tetragonal to hexagonal phase occurs. The EPR feature corresponding to $\mathrm{Ti}^{3+}$ decreases progressively as the $\mathrm{Gd}$ content increases, which implies a decrease of the oxygen vacancy concentration. This facilitates reentrant tetragonal phase conversion. The observed ferromagnetic nature originated from the $\mathrm{Fe}^{3+}-\mathrm{O}^{2-}-\mathrm{Fe}^{3+}$ super-exchange and $\mathrm{Gd}^{3+}-\mathrm{O}^{2-}-\mathrm{Gd}^{3+}$ interactions. The artificial single tetragonal phase magnetoelectric $\mathrm{Ba}_{0.985} \mathrm{Gd}_{0.015} \mathrm{Ti}_{0.95} \mathrm{Fe}_{0.05} \mathrm{O}_{3}$ material has the excellent magnetoelectric coupling coefficient of $3.74 \mathrm{mV} / \mathrm{cm}$. Oe.

\section{Introduction}

Nowadays, the manufacture of advanced multifunctional materials is much more attractive because of the coexistence of charge and spin control in the same material. The simultaneous tuning of two ferroic orders has much attraction, which shows the magneto-electric (ME) effect in the sample. The design of a single-phase multiferroic material is difficult because of the formation of secondary phases, which weakens the ferroelectric (FE) and ferromagnetic (FM) properties. To compensate for the rarity, the preparation of new and artificial multifunctional materials focused on the path of composites [1-3], heterostructure [4-6], and magnetism imposed FE materials [7, 8].

For the preparation of artificial multifunctional material, the role of $\mathrm{BaTiO}_{3}$ (BTO) is much more attractive due to the better polarisation property. BTO based composites, heterostructure materials, and transition metal (TM) implanted has already extensively reported [9-25]. BTO-CFO composites exhibit better multiferroic property through strain mediated ME coupling, which is attributed from the piezoelectric strain and a decrease in polarisation [2]. The origin of the ME effect is drastically influenced by the defect formation. Therefore, the researchers would like to modify the parent phase with A-site [13-15, 18-20], Bsite $[8,11,12]$, or both A\&B-site co-doping $[15,17]$. Dopant's ionic radius, charge, magnetic moment and site change the ferroelectric order, leakage current, dielectric characteristics, instill magnetic order in the robust ferroelectric host (BTO), and thus pave the way to understand the magneto-electric effect. A-site donor $\left(\mathrm{La}^{3+}\right)$ doping in $\mathrm{BTO}$ with tetragonal $(\mathrm{T})$ symmetry enhances the polarisation by reducing the leakage current, which arises from the suppression of defect concentration, whereas, cubic phase restricts the polarisation due to the impediment of domain wall switching. B-site donor doping suppresses the polarisation and significantly improves the magnetisation through exchange interactions. While the B-site homovalent $\left(\mathrm{Sn}^{4+}\right)$ doping improves the polarisation and electrocaloric properties by the 
influence of microstructure and doping quantity [14]. A-site co-doping in BTO with $\mathrm{Sr}^{3+}-\mathrm{Ca}^{2+}$ exhibits enhancement in polarisation by the increase in tetragonality (c/a ratio) and development of strain [15]. Acceptor doping of TM in B-site of BTO charge imbalance promotes the oxygen vacancies that enhance the FM property, and lattice strain is responsible for the ME coupling through magnetostriction [8]. The nature of the magnetisation in the TM co-doped BTO system depends on the preparation condition. Lin et. al. has reported the paramagnetic (PM) to ferromagnetic (FM) phase transition in $\mathrm{TM}(\mathrm{Cr}, \mathrm{Fe}, \mathrm{Mn} \& \mathrm{Ni})$ co-doped BTO under the annealing in vacuum medium [16]. However, the polarisation not improved in Mn-Fe co-doping in B-site [17]. Simultaneous substitution of magnet element in A-site (donor) and B-site (acceptor) are effective and enhance the ME property by removing defects and increasing the magnetic moment. The co-substitution of $\mathrm{Eu}^{3+}-\mathrm{Cr}^{3+}, \mathrm{Sm}^{3+}-\mathrm{Fe}^{3+}, \mathrm{Gd}^{3+}-\mathrm{Fe}^{3+}$ and $\mathrm{Dy}^{3+}-\mathrm{Fe}^{3+}$ have already been reported with improved dielectric, polarisation, and ME properties respectively [18-21]. Even so, the origin of magnetisation and ME coupling is unclear in the RE-TM co-substituted BTO system except Dy ${ }^{3+}-\mathrm{Fe}^{3+} \mathrm{co}^{-}$ substituted BTO [21]. The current work, co-substitution of $\mathrm{Gd}^{3+}-\mathrm{Fe}^{3+}$ in A-site and B-site respectively on BTO ceramics elucidate in detail, the origin of magnetism and ME coupling.

\section{Material And Methods}

$\mathrm{Ba}_{1-\mathrm{y}} \mathrm{Gd}_{\mathrm{y}} \mathrm{Ti}_{1-\mathrm{x}} \mathrm{Fe}_{\mathrm{x}} \mathrm{O}_{3}(\mathrm{x}=0.05 ; \mathrm{y}=0.005,0.01$ and 0.015$)$ ceramics are synthesized via a mixed-oxide route. Precursors of $\mathrm{BaCO}_{3}, \mathrm{Gd}_{2} \mathrm{O}_{3}, \mathrm{TiO}_{2}$, and $\mathrm{Fe}_{2} \mathrm{O}_{3}$ with high purity $(99.9 \%)$ are required to prepare the multifunctional materials. In a hot air oven, the selected precursors are pre-heated at $60^{\circ} \mathrm{C}$ for 24 hours. In an agate mortar and pestle, the stoichiometric ratio of the precursors is weighed and pulverised for 30 minutes. It is pre-sintered at $1050^{\circ} \mathrm{C}$ for 4 hours before being re-grounded. For the formation of pellets using a hydraulic pellet press, a polyvinyl alcohol (PVA) gel is added as a binder to the calcined powder, and the green pellets are sintered at $1370^{\circ} \mathrm{C}$ for 2 hours. The pellets are polished before being coated with silver and then heated at $100^{\circ} \mathrm{C}$ for 12 hours to improve electrode adherence.

The structure is characterized using a PAN alytical XPert Pro powder X-ray diffractometer equipment that recorded the diffraction pattern over a range of $2 \theta$ from $10^{\circ}$ to $90^{\circ}$. JANA2006 software is used to refine the XRD data [22]. High-resolution transmission electron microscopy is used to record SAED patterns for structural coexistence (JEOL JEM 2100). The vacancy distribution is determined via electron paramagnetic resonance analysis (JEOL-JES-FA200). The oxidation state of the elements contained in the sample is determined using an X-ray photoelectron spectroscopy spectrum (PHI - VERSAPROBE III). Using a ferroelectric loop tracer, a ferroelectric loop was recorded (Radiant technologies). A vibrating sample magnetometer equipment is used to investigate magnetic behaviour (Lakeshore-7410 series). An impedance analyzer was used to measure magnetodielectric properties with and without a magnetic field as a function of frequency (CHI 604A). The lock-in amplifier method is used to perform magnetoelectric measurements.

\section{Results And Discussion}


In order to identify the crystalline structure of the as-prepared ceramics, analysis of the powder XRD data is performed. Figure $1 \mathrm{a}$ displays the laboratory PXRD patterns of the $\mathrm{Ba}_{1-\mathrm{y}} \mathrm{Gd}_{\mathrm{y}} \mathrm{Ti}_{1-\mathrm{x}} \mathrm{Fe}_{\mathrm{x}} \mathrm{O}_{3}(\mathrm{x}=0.05 ; \mathrm{y}=$ $0.005,0.01$ and 0.015 ) ceramics. In general, $\mathrm{BaTiO}_{3}$ undergoes a distinct structural transformation with respect to the temperature such as rhombohedral (R3c) to orthorhombic (Amm2), orthorhombic to tetragonal (P4mm), and tetragonal to cubic (Pm3m) phase transition. $\mathrm{BaTi}_{0.95} \mathrm{Fe}_{0.05} \mathrm{O}_{3-\delta}$ ceramics shows both tetragonal $(\mathrm{P} 4 \mathrm{~mm})$ and hexagonal $\left(\mathrm{PG}_{3} / \mathrm{mmc}\right)$ phases with a phase percentage of $59 \%$ and $41 \%$ respectively [23]. The powder XRD profiles are matched with the JCPDS card no. of 05-0626 (P4mm) and 34-0129 $\left(\mathrm{PG}_{3} / \mathrm{mmc}\right)$ and no evidence for the secondary phases likely, $\mathrm{GdFeO}_{3}$ and unreacted starting oxides. The structural coexistence of tetragonal + hexagonal $(T+H)$ observed in $y=0.005 \& 0.01$ ceramics whereas, single T-phase alone in $y=0.015$ ceramics. Similar structure has already reported in $\mathrm{Dy}^{3+}-\mathrm{Fe}^{3+}$ co-substituted BTO [21]. The occurrence of the structure coexistence with respect to the Gdcontent indicates the morphotropic phase boundary (MPB). The diffraction patterns indicate a slight peak shifting towards the higher $2 \theta$ which is attributed to the mismatch of the ionic radius in A-site ions i.e. $\mathrm{Ba}^{2+}(1.35 \AA ̊)$ and $\mathrm{Gd}^{3+}(0.938 \AA)$.

Due to the lack of visibility to identify the presence of phase, either tetragonal or cubic should be used through the (002)/ (200) splitting, Gaussian fitting is used in the vicinity of $45^{\circ}$ as shown in Fig. $1 \mathrm{~b}$. Asymmetrical diffraction confirms the presence of the tetragonal phase in the lattice in all of the samples. The decline of $\mathrm{H}$-phase $(\mathrm{H}(204))$ intensity indicates that the instability of $\mathrm{H}$-phase is triggered under the Gd-substitution. This suggests a decrease of defect content in ceramics, because the H-phase accepts more oxygen vacancies due to the presence of the oxygen bridge in the unit cell. The incorporation of $\mathrm{Gd}$-content leads to the structural transformation from the coexistence of metastable $\mathrm{H}$ phase and stable T-phase that suppresses the defect concentration.

The structural details yielded from the Rietveld refinement for $\mathrm{Ba}_{1-y} \mathrm{Gd}_{y} \mathrm{Ti}_{1-\mathrm{x}} \mathrm{Fe}_{\mathrm{x}} \mathrm{O}_{3}(\mathrm{x}=0.05 ; \mathrm{y}=0.005$, 0.01 and 0.015 ) ceramics are shown in Fig. 2. For the tetragonal phase with the space group of P4mm, four ions $\mathrm{Ba}^{2+} / \mathrm{Gd}^{3+}, \mathrm{Ti}^{4+}, \mathrm{Fe}^{3+}$ and $\mathrm{O}^{2-}$, occupy the three distinct Wyckoff positions. $\mathrm{Ba} 1$ at the (1a) site, $\mathrm{Ti}^{4+} / \mathrm{Fe}^{3+}$ at the (1b) site, 01 at the (1b) site and 02 at the (2c) site with the positional coordinates of $(0,0,0),(1 / 2,1 / 2, z),(1 / 2,1 / 2, z)$ and $(0,1 / 2, z)$ respectively. For the hexagonal phase with the space group of $\mathrm{P}_{3} / \mathrm{mmc}$, four ions $\mathrm{Ba}^{2+} / \mathrm{Gd}^{3+}, \mathrm{Ti}^{4+} / \mathrm{Fe}^{3+}$ and $\mathrm{O}^{2-}$ occupy the five distinct Wyckoff sites. Bal at the (2b) site, $\mathrm{Ba} 2$ at the (4f) site, $\mathrm{Ti}^{4+} / \mathrm{Fe}^{3+}$ at the (2a) site, $\mathrm{Ti}^{4+} / \mathrm{Fe}^{3+}$ at the (4f) site, 01 at the (6h) site and 02 at the (12k) site with the positional coordinates of $(0,0,1 / 4),(1 / 3,2 / 3, z),(0,0,0),(/ 1 / 3,2 / 3, z),(x, y, 3 / 4)$ and $(x, y, z)$ respectively. The sequence of the fitting has already been reported in BTO substituted BFO [24]. $\mathrm{T}(\mathrm{P} 4 \mathrm{~mm})+\mathrm{H}\left(\mathrm{P \sigma}_{3} / \mathrm{mmc}\right)$ for $\mathrm{y}=0.005 \& 0.01$ and $\mathrm{T}(\mathrm{P} 4 \mathrm{~mm})$ for $\mathrm{y}=0.015$ profile models give the better fitting with less $\chi^{2}$ compared with other models like, $\mathrm{T}(\mathrm{P} 4 \mathrm{~mm}), \mathrm{H}\left(\mathrm{P}_{3} / \mathrm{mmc}\right), \mathrm{C}(\mathrm{Pm} 3 \mathrm{~m})$ and $\mathrm{C}(\mathrm{Pm} 3 \mathrm{~m})+$ $\mathrm{H}\left(\mathrm{PG}_{3} / \mathrm{mmc}\right)$. In which, the positional coordinates are taken from the standard crystallographic Table [25]. The structural parameters, volume phase percentage, and bond length listed are in Table 1. The increase in $c / a$ ratio is consented to the increase in tetragonal phase percentage as an increase of Gd-content. The 
average grain size (D) calculated using Scherrer's formula and listed in Table 1. As the Gd-content increases, the average grain size gradually declines, suggesting that $\mathrm{Gd}$-content is not able to support grain growth.

Table 1: Structural parameters such as cell values, c/a ratio, phase percentage, crystallite size, microstrain, dislocation density and bond length of the $\mathrm{Ba}_{1-y} \mathrm{Gd}_{y} \mathrm{Ti}_{1-\mathrm{x}} \mathrm{Fe}_{\mathrm{x}} \mathrm{O}_{3} ; \mathrm{x}=0.05 ; \mathrm{y}=0.005,0.01$ and 0.015 ceramics

\begin{tabular}{|c|c|c|c|c|c|}
\hline & \multicolumn{2}{|c|}{$x=0.05 ; y=0.005$} & \multicolumn{2}{|c|}{$x=0.05 ; y=0.01$} & \multirow{2}{*}{$\begin{array}{l}x=0.05 ; y=0.015 \\
P 4 m m\end{array}$} \\
\hline Crystal symmetry & $\mathrm{P} 4 \mathrm{~mm}$ & $\mathrm{P}_{3} / \mathrm{mmc}$ & $\mathrm{P} 4 \mathrm{~mm}$ & $\mathrm{P}_{3} / \mathrm{mmc}$ & \\
\hline$a(\AA)$ & 3.999 & 5.715 & 3.998 & 5.715 & 3.995 \\
\hline$c(\AA)$ & 4.006 & 13.999 & 4.007 & 14.003 & 4.005 \\
\hline$V(\AA)^{3}$ & 64.1 & 396 & 64 & 396.1 & 63.9 \\
\hline c/a ratio & 1.0017 & - & 1.0021 & - & 1.0024 \\
\hline Phase \% & 82.2 & 17.8 & 99.07 & 0.93 & 100 \\
\hline $\mathrm{D}(\mathrm{nm})$ & 82 & & 67 & & 57 \\
\hline$\varepsilon\left(10^{-3}\right)(\mathrm{nm})^{-2}$ & 1.810 & & 1.808 & & 2.038 \\
\hline$\delta\left(10^{-3}\right)$ & 0.494 & & 0.236 & & 0.345 \\
\hline Gd2-04 & - & 2.884 & - & 2.69 & - \\
\hline Gd3-O4 & - & 1.757 & - & 2.89 & - \\
\hline Fe3-04 & - & 1.691 & - & 1.476 & - \\
\hline
\end{tabular}

Figure 3(a-c) displays the HR-TEM micrographs of the as-prepared $\mathrm{Ba}_{1-\mathrm{y}} \mathrm{Gd}_{\mathrm{y}} \mathrm{Ti}_{1-\mathrm{x}} \mathrm{Fe}_{\mathrm{x}} \mathrm{O}_{3}(\mathrm{x}=0.05 ; \mathrm{y}=$ $0.005,0.01$ and 0.015$)$ ceramics. The micrographs show much more dislocations and grain boundary (GB) with bulging. In general, in order to understand the formation of dynamic recrystallisation (DRX) grains, the micro-strain and dislocation density are much more important. The micro-strain $(\varepsilon)$ and dislocation density $(\delta)$ are calculated using XRD data by the following formula as $\epsilon=1 / D^{2}\left(n m^{-2}\right)$, where D-crystallite size ( $\mathrm{nm}$ ) and $\delta=\beta / \tan \theta$, where $\beta$ - FWHM (deg.), $\theta$-diffraction angle (deg.) respectively. The values of $D, \beta$, and $\theta$ are obtained from XRD data and the calculated values of $\varepsilon$ and $\delta$ are listed in Table 1 . Both of the $\varepsilon$ and $\delta$ values decreased up to $y=0.01$ ceramics and then they increased with the further increase of Gd-content. A lower strain value suppresses the formation of lower angel GBs (LAGBs) that restricts the onset of DRX grain growth [26, 27]. The serrated GB in $y=0.01$ ceramics is due to the low value of $\varepsilon$ that leads to the unfeasibility of the DRX grain growth. Since, lower strain value produces less strain energy, which is not sufficient to reorder the dislocations near the GBs. However, serrated GB is a good location for the GB elongation, which facilitates the nucleation process. 
The complete growth of DRX occurs after the disappearance of GB bulging with the further increase of strain rate 1.2 [26] that obliterated the dislocations. Even though the increase of strain, the DRX growth is not evidenced in the $y=0.015$ sample. Because the strain energy is much higher than the required level for the deformation because of the time limitation which results in heterogeneous grains.

Figure 4(a-c) shows the HREM of the $\mathrm{Ba}_{1-y} \mathrm{Gd}_{y} \mathrm{Ti}_{1-x} \mathrm{Fe}_{\mathrm{x}} \mathrm{O}_{3}(\mathrm{x}=0.05 ; \mathrm{y}=0.005,0.01$ and 0.015$)$ ceramics. The clear lattice fringes confirm the high crystallinity of the ceramics. The lattice fringes with $\mathrm{d}$-spacing of $0.404 \mathrm{~nm}$ is for the H-phase of $\mathrm{y}=0.005$ and correspond to the (102) plane. The other two ceramics ( $y$ $=0.01 \& 0.015$ ) confirm the presence of the T-phase with the $\mathrm{d}$-spacing of $0.284 \mathrm{~nm}, 0.282 \mathrm{~nm}$ that correspond to the (101) and (110) plane respectively. Figure 5(a-c) displays the SAED patterns of $\mathrm{Ba}_{1-}$ ${ }_{y} \mathrm{Gd}_{\mathrm{y}} \mathrm{Ti}_{1-\mathrm{x}} \mathrm{Fe}_{\mathrm{x}} \mathrm{O}_{3}(\mathrm{x}=0.05 ; \mathrm{y}=0.005,0.01$ and 0.015$)$ ceramics, along the $[010]_{\mathrm{PC}}$ zone axis. Structural coexistence of the $\mathrm{T}+\mathrm{H}$ phase is confirmed in $\mathrm{y}=0.005,0.01$ ceramics and $\mathrm{y}=0.015$ ceramics shows the T-phase alone. The aforementioned HREM and SAED investigations are concurrence with the XRD results.

Figure 6 illustrates the core-level spectra of $\mathrm{Ba}, \mathrm{Gd}, \mathrm{Ti}, \mathrm{Fe}$, and $\mathrm{O}$ elements in the $\mathrm{Ba}_{0.995} \mathrm{Gd}_{0.005} \mathrm{Ti}_{0.95} \mathrm{Fe}_{0.05} \mathrm{O}_{3}$ ceramics. To find out the accurate binding energy (B.E) positions of the elements Gaussian function was used for peak fitting. In the Ba $3 \mathrm{~d}$ core-spectrum, the peaks at $779.71 \mathrm{eV}$ correspond to the $\mathrm{Ba} 3 \mathrm{~d}_{5 / 2}$ and $795.04 \mathrm{eV}$ assigns to the $\mathrm{Ba} 3 \mathrm{~d}_{3 / 2}$ spin-orbit doublet. The energy separation between the Ba spin-orbit doublets is $15.33 \mathrm{eV}$ [28]. In the core-level spectra of Ti $2 p$, the binding energy position of $\mathrm{Ti} 2 \mathrm{p}_{3 / 2}$ and $\mathrm{Ti} 2 \mathrm{p}_{1 / 2}$ are obtained at $459.2 \mathrm{eV}$ and $464.80 \mathrm{eV}$ respectively, and the weak reflection at $457.8 \mathrm{eV}$ assigned to $\mathrm{Ti}^{3+}$. The energy separation of $\mathrm{Ti} 2 \mathrm{P}$ doublet is $5.6 \mathrm{eV}$, which is correlated to the literature $[29,30]$. The asymmetric nature of the $\mathrm{Gd} 4 \mathrm{~d}$ spectrum indicates the spin-orbit doublets of $\mathrm{Gd}$ i.e $\mathrm{Gd} 4 \mathrm{~d}_{5 / 2}$ and $\mathrm{Gd} 4 \mathrm{~d}_{3 / 2}$, which presented at the B.E positions of $141.8 \mathrm{eV}$ and $146 \mathrm{eV}$ that agree with the literature [28]. The $01 \mathrm{~s}$ spectrum fitted at four B.E positions and the B.Es are $529.49 \mathrm{eV}$, $530.67 \mathrm{eV}, 532.59 \mathrm{eV}$ and $533.99 \mathrm{eV}$. The peak at $529.49 \mathrm{eV}$ confirms the metal-oxygen bond that is lattice oxygen and the peak at $530.67 \mathrm{eV}$ corresponds to the dangling bond i.e. oxygen vacancy. The other two reflections at $532.59 \mathrm{eV}$ and $533.99 \mathrm{eV}$ indicate that the O-Gd and Gd-O-Gd respectively. As a result, XPS core spectra confirm the incorporation of $\mathrm{Gd}$ at Ba-site and Fe at Ti-site in the as-prepared ceramics.

Figure 7 reveals the EPR spectrum as prepared of $\mathrm{Ba}_{1-y} \mathrm{Gd}_{y} \mathrm{Ti}_{1-x} \mathrm{Fe}_{\mathrm{x}} \mathrm{O}_{3}(\mathrm{x}=0.05 ; \mathrm{y}=0.005,0.01$ and $0.015)$ ceramics. A strong asymmetric single EPR feature was noticed in all the ceramics. The calculated gyromagnetic $(\mathrm{g})$ factors are listed in Table 2 . These signals corresponding to $\mathrm{Ti}^{3+}$ paramagnetic defect matched with the literature [31-33]. The signal gradually decreases as it increases in $\mathrm{Gd}$ - content that suggests the Gd-substitution to try to suppress the generation of $\mathrm{Ti}^{3+}$ ion that implies the removal of $\mathrm{Fe}^{2+}$. On the other hand, the tetragonal and cubic phase EPR signal are featureless which Kondiazhuyi et.al, has already reported [31]. The change in intensity depends on the defect valence state, low to high spin configuration, and spin-lattice relaxation time [33]. The wide and less intense signals are observed with the g-factor of 6.244 and 1.613, which are associated with $\mathrm{Fe}^{2+}$ ion and are weak with the further increase of Gd-content. Moreover, the EPR signals which did not shift towards the $\mathrm{g}=2.00$ signal indicate that $\mathrm{Gd}$ substitution does not affect the T-crystal symmetry. From that, Gd-substitution controls the defect 
formation through the charge compensation process. Spin-orbit coupling is confirmed by the slight deviation of the $g$-factor from the standard $g$-factor of the unpaired electrons [34]. $\Delta B_{P-P}$ is the width of the signal that creates the separation between the upper and lowers the lower peak [35]. A higher value of line-width parameters $\left(\Delta \mathrm{B}_{\mathrm{P}-\mathrm{P}}\right)$ suggests strong magnetic dipolar interaction within the sample and is tabulated (Table 2).

Table 2

EPR parameters such as g-factor, $\Delta \mathrm{g} / \mathrm{g}, \Delta \mathrm{B}_{\mathrm{P}-\mathrm{P}}$ and $\mathrm{P}_{\text {asy }}$ of the $\mathrm{Ba}_{1-\mathrm{y}} \mathrm{Gd}_{\mathrm{y}} \mathrm{Ti}_{1-\mathrm{x}} \mathrm{Fe}_{\mathrm{x}} \mathrm{O}_{3} ; \mathrm{x}=$ $0.05 ; y=0.005,0.01$ and 0.015 ceramics

\begin{tabular}{|c|c|c|c|c|c|}
\hline \multirow[b]{2}{*}{ Crystal symmetry } & \multicolumn{2}{|c|}{$x=0.05 ; y=0.005$} & \multicolumn{2}{|c|}{$x=0.05 ; y=0.01$} & \multirow{2}{*}{$\begin{array}{l}x=0.05 ; y=0.015 \\
P 4 m m\end{array}$} \\
\hline & $\mathrm{P} 4 \mathrm{~mm}$ & $\mathrm{P}_{3} / \mathrm{mmc}$ & $\mathrm{P} 4 \mathrm{~mm}$ & $\mathrm{P}_{3} / \mathrm{mmc}$ & \\
\hline$a(\AA)$ & 3.999 & 5.715 & 3.998 & 5.715 & 3.995 \\
\hline$c(\AA)$ & 4.006 & 13.999 & 4.007 & 14.003 & 4.005 \\
\hline$V(\AA)^{3}$ & 64.1 & 396 & 64 & 396.1 & 63.9 \\
\hline$c / a$ ratio & 1.0017 & - & 1.0021 & - & 1.0024 \\
\hline Phase \% & 82.2 & 17.8 & 99.07 & 0.93 & 100 \\
\hline $\mathrm{D}(\mathrm{nm})$ & 82 & & 67 & & 57 \\
\hline$\varepsilon\left(10^{-3}\right)(\mathrm{nm})^{-2}$ & 1.810 & & 1.808 & & 2.038 \\
\hline$\delta\left(10^{-3}\right)$ & 0.494 & & 0.236 & & 0.345 \\
\hline Gd2-04 & - & 2.884 & - & 2.69 & - \\
\hline Gd3-04 & - & 1.757 & - & 2.89 & - \\
\hline Fe3-04 & - & 1.691 & - & 1.476 & - \\
\hline
\end{tabular}

Furthermore, the EPR study was also used to understand the presence of magneto-crystalline anisotropy in the samples through the asymmetric parameter $\left(P_{\text {asy }}\right)$. It is calculated from the following relation, $P_{\text {asy }}$ $=\left[1-\frac{h_{U}}{h_{L}}\right]$, Where $h_{U}$-maximum height of the upper peak above the baseline (cts.), $h_{L}-$ maximum height of the lower peak below the baseline (cts.). The calculated values are tabulated in Table 2. As an increase of Gd-content, the values of $P_{\text {asy }}$ decrease, and a high value obtained in $\mathrm{y}=0.005$ ceramics which denotes that the strong magnetic interaction is expected in that sample $(y=0.005)$ through magnetocrystalline anisotropy. In addition, magneto-crystalline anisotropy of $\mathrm{Fe}^{3+}$ in $2 \mathrm{~b}$-site $\left(1.4 \mathrm{~cm}^{-1} /\right.$ ion $)$ is significantly higher than the $12 \mathrm{k}$-site $\left(-0.18 \mathrm{~cm}^{-1} / \mathrm{ion}\right)$ that has already been reported in TM doped barium ferrite system [36]. The bond length of Gd2-04 (Gd2 at 2b-site) $>$ Gd3-04 (Gd3 at 12k-site) for $y=0.005$ ceramics 
and Gd2-04 (2b-site) < Gd3-04 (12k-site). The reduction in the length of the Gd-O bond strengthens the Gd-O bond, which favors strong magnetization. In this sense, the $12 \mathrm{k}$-site unable to exhibit high magnetocrystalline anisotropy than $2 \mathrm{~b}$-site, which is concurrence to the asymmetric parameter $\left(\mathrm{P}_{\text {asy }}\right)$.

Figure 8(a-c) shows the polarisation (P)-electric field $(E)$ hysteresis loops of $\mathrm{Ba}_{1-y} \mathrm{Gd}_{\mathrm{y}} \mathrm{Ti}_{1-\mathrm{x}} \mathrm{Fe}_{\mathrm{x}} \mathrm{O}_{3}(\mathrm{x}=0.05$; $y=0.005,0.01$ and 0.015$)$ ceramics. The unsaturated loops are noticed in all the ceramics even at the high electric field of $40 \mathrm{kV} / \mathrm{cm}$, which indicates the leaky-like behaviour. The value of remnant polarisation $\left(P_{r}\right)$ non-monotonously varied and the large value of $P_{r}$ is noticed in $y=0.01$ ceramics. Because of the decline in the paraelectric phase, a decrease of the H-phase improves polarisation. Even though the increase of tetragonality ( $c / a$ ratio), the $y=0.015$ ceramics are unable to exhibit better polarisation due to the B-side defect that produces oxygen vacancy for charge compensation. The decline in coercive field $\left(E_{c}\right)$ indicates the softness of the ceramics. The ferroelectric parameters i.e. $P_{r}, P_{\text {max }}$, and $E_{c}$ are listed in Table 3. The enhancement of polarisation manifests the reduction in defect concentration by Gdconcentration. Both of the XPS and EPR investigations support the presence of B-site defect i.e. $\mathrm{Ti}^{3+} / \mathrm{Fe}^{2+}$ in the samples and the defect concentration decrease as an increase of $\mathrm{Gd}$-content. Because the dissociation energy of $\mathrm{Gd}-\mathrm{O}$ bond $(719 \pm 6 \mathrm{~kJ} / \mathrm{mol})$ is much higher than the Ba-O $(562 \pm 42 \mathrm{~kJ} / \mathrm{mol})$, which suppresses the defect formation $[37,38]$.

Table 3: Ferroelectric and ferromagnetic parameters such as remnant polarisation, maximum polarisation, coercive field and remnant magnetisation, squareness of the loop, coercive field respectively of the $\mathrm{Ba}_{1-\mathrm{y}} \mathrm{Gd}_{\mathrm{y}} \mathrm{Ti}_{1-\mathrm{x}} \mathrm{Fe}_{\mathrm{x}} \mathrm{O}_{3} ; \mathrm{x}=0.05 ; \mathrm{y}=0.005,0.01$ and 0.015 ceramics

\begin{tabular}{lllllll} 
y-content & $P_{r}\left(\mu \mathrm{C} / \mathrm{cm}^{2}\right)$ & $P_{\max }\left(\mu \mathrm{C} / \mathrm{cm}^{2}\right)$ & $E_{c}(\mathrm{kV} / \mathrm{cm})$ & $\mathrm{M}_{\mathrm{r}}(\mathrm{memu} / \mathrm{g})$ & $\mathrm{M}_{\mathrm{r}} / \mathrm{M}_{\mathrm{s}}$ & $\mathrm{H}_{\mathrm{c}}(\mathrm{kOe})$. \\
\hline 0.005 & 1.65 & 5.93 & 6.35 & 2.325 & 0.282 & 0.408 \\
\hline 0.01 & 2.44 & 10.52 & 4.79 & 2.812 & 0.274 & 0.653 \\
\hline 0.015 & 1.89 & 9.17 & 4.53 & 4.127 & 0.262 & 0.968
\end{tabular}

Table 4: Extrinsic, intrinsic magnetodielectric constant (MDC) and magnetoelectric coupling coefficient $\left(\mathrm{a}_{\mathrm{ME}}\right)$ values of the $\mathrm{Ba}_{1-\mathrm{y}} \mathrm{Gd}_{\mathrm{y}} \mathrm{Ti}_{1-\mathrm{x}} \mathrm{Fe}_{\mathrm{x}} \mathrm{O}_{3} ; \mathrm{x}=0.05 ; \mathrm{y}=0.005,0.01$ and 0.015 ceramics

\begin{tabular}{llll} 
y-content & Extrinsic MDC \% & Intrinsic MDC \% & $\mathrm{a}_{\mathrm{ME}}(\mathrm{mV} / \mathrm{cm} . \mathrm{Oe})$ \\
\hline 0.005 & -2.53 & -0.51 & 5.42 \\
0.01 & -2.33 & -0.31 & 3.32 \\
0.015 & -1.97 & -0.36 & 3.74
\end{tabular}

Magnetisation (M)-magnetic field $(\mathrm{H})$ hysteresis loops of $\mathrm{Ba}_{1-\mathrm{y}} \mathrm{Gd}_{\mathrm{y}} \mathrm{Ti}_{1-\mathrm{x}} \mathrm{Fe}_{\mathrm{x}} \mathrm{O}_{3}(\mathrm{x}=0.05 ; \mathrm{y}=0.005,0.01$ and 0.015$)$ ceramics shown in Fig. 9(a-c). It is clear that all the ceramics show well-saturated loops, which denotes the ferromagnetic (FM) feature. The inserts of Fig. 9(a-c) reveal the ABK plots, which confirms the FM behaviour through the convex curvature. Pristine BTO exhibits weak FM due to the B-site 
vacancy i.e. $\mathrm{Ti}^{3+}$ [39-43]. In view of the literature, the nanosized BTO shows weak FM due to the formation of $\mathrm{Ti}^{3+}$, the intrinsic defect [42-45]. As the increase of Gd-concentration, both $\mathrm{M}_{\mathrm{r}}$ and $\mathrm{M}_{\mathrm{s}}$ simultaneously improved, while the squareness of the loops $\left(M_{r} / M_{s}\right)$ decreases. In this work, the observed $\mathrm{M}_{\mathrm{r}}$ is larger than that of $\mathrm{Dy}^{3+}-\mathrm{Fe}^{3+}$ co-substituted BTO [21]. The increase of the coercive field $\left(\mathrm{H}_{\mathrm{c}}\right)$ envisages the magnetic hardness of the sample. Both $M_{r}$ and $H_{c}$ are significantly enhanced even though there is the supremacy of the T-phase. The structural distortion arises from the large mismatch of ionic

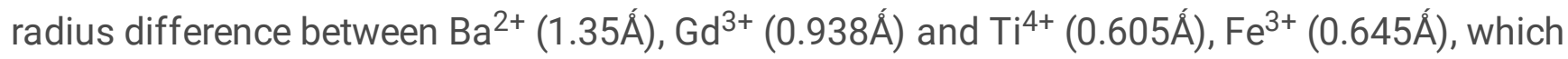
strengthens the Fe-O-Fe bond. Moreover, the substitution of magnetic Gd element $(7.8 \mu \mathrm{B})$ in Ba-site enhances the magnetisation.

In general, the origin of ferromagnetism depends on the various kinds of magnetic interactions such as, (i) octahedral $\mathrm{Fe}^{3+}$-octahedral $\mathrm{Fe}^{3+}$ interaction (ii) pentahedral $\mathrm{Fe}^{3+}$ - pentahedral $\mathrm{Fe}^{3+}$ interaction (iii) $\mathrm{Fe}^{2+}-\mathrm{Fe}^{3+}$ and $\mathrm{Fe}^{3+}-\mathrm{Fe}^{4+}$ double exchange interactions and (iv) pentahedral $\mathrm{Fe}^{3+}$ - octahedral $\mathrm{Fe}^{3+}$ interaction. XPS core-level spectra of Fe 2P (Fig. 6) evidences the aliovalent feature of the Fe element i.e. $\mathrm{Fe}^{2+} / \mathrm{Fe}^{3+}$, which induces the magnetisation through $\mathrm{Fe}^{2+}-\mathrm{O}^{2-}-\mathrm{Fe}^{3+}$ double-exchange interaction. Nevertheless, EPR investigation indicates that the defect signal intensity gradually decreases with the increase of Gd-concentration, which implies the feasibility of double-exchange interaction weak upon Gdconcentration. Even though the inadequate of $\mathrm{Fe}^{2+}-\mathrm{O}^{2-}-\mathrm{Fe}^{3+}$ double-exchange interaction, the magnetisation significantly enhanced this symbolizes the possibility of super-exchange interactions. The bond length of $\mathrm{Fe} 3-04$ gradually reduces which manifests the strong bonding force in Fe3-04 that much more strengthens the $\mathrm{Fe} 3-04$ bond. This strengthens the super-exchange interaction $\mathrm{Fe}^{3+}-\mathrm{O}^{2-}-\mathrm{Fe}^{3+}$ that promotes the magnetisation. Moreover, Gd-substitution superimposed a new interaction between $\mathrm{Gd}^{3+}$ $\mathrm{O}^{2-}-\mathrm{Gd}^{3+}$ along with Fe-Fe interactions also contributes the magnetisation. In La, Ho \& Gd doped BFO system, the new magnetic interaction of $\mathrm{Ho}-\mathrm{Fe}, \mathrm{Ho}-\mathrm{Ho}$ through the oxygen brings the magnetisation along with Fe-Fe interaction [44]. In Fe-enforced BTO, the observed ferromagnetisation depends on the structural heterogeneity [23] whereas; in this present case, it is independent of the structural heterogeneity $(T+H$ phase) since $M_{r}$ improved as the increase of T-phase. Therefore, the observed magnetisation entirely originated from the co-contribution of $\mathrm{Fe}^{3+}-\mathrm{O}^{2-}-\mathrm{Fe}^{3+}$ super-exchange interactions and a new $\mathrm{Gd}^{3+}-\mathrm{O}^{2-}-$ $\mathrm{Gd}^{3+}$ interaction.

Figure 10(a-c) displays the magnetodielectric constant as a function frequency $\left(10^{0}-10^{6} \mathrm{~Hz}\right)$. The magnetodielectric effect consists of distinct origin such as, extrinsic MD effect and intrinsic MD effect, which classified from the response as a function of frequency [23]. The observed MD constant is large and negative among the TM-RE co-substituted BTO systems. An increase of Gd-content, the extrinsic MD constant monotonously decreased. To understand the lower frequency dispersion trend, the investigation of the dielectric dispersion without an applied magnetic field as a function frequency is required which has already been reported [23]. At lower frequency $\left(10^{2} \mathrm{~Hz}\right)$, the observed MD constant obeys with the applied magnetic field whereas, as the frequency increases the MD constant remains relatively constant. This strongly confirms the low frequency magnetodielectric dispersion due to the presence of space 
charge polarisation. XPS and EPR investigations confirmed the presence of point defects in the ceramics. Thus, the trapping of electrons at the oxygen vacancy sites promotes the space charge polarisation. The degradation of the concentration of point defects by the suppression of structural heterogeneity due to the increase of $\mathrm{Gd}^{3+}$ weakens the space charge polarisation that decreases the MD constant.

Figure 11(a-c) depicts the intrinsic magnetodielectric constant as a function of an applied magnetic field at $1 \mathrm{MHz}$ of frequency. With an increase in Gd-content, the intrinsic MD constant gradually decreases up to $y=0.01$ ceramic then it increases. The lesser value of intrinsic magnetodielectric constants at IT are obtained and listed in Table 3. The intrinsic MD constant of Fe-substituted BTO ceramics is $-3.7 \%$ where the sample calcination and sintering temperatures are $950^{\circ} \mathrm{C} / 5 \mathrm{~h}$ and $1300^{\circ} \mathrm{C} / 2 \mathrm{~h}$ that has already been reported [23]. In this work, there is only less value of intrinsic magnetodielectric constant due to the high calcination temperature of $1050^{\circ} \mathrm{C} / 4 \mathrm{~h}$ and sintering temperature of $1370^{\circ} \mathrm{C} / 2 \mathrm{~h}$ that stabilizes the $\mathrm{H}-$ phase through the generation of oxygen vacancies. The observed weak intrinsic magnetodielectric constant is originated from the strain-induced magneto-electric coupling through the magnetostriction.

The above-mentioned explanations indicate that the magnetoelectric coupling (ME) is plausible i.e coupling between magnetic and ferroelectric order in the sample. In general, ME measurement is carried out by the lock-in-amplifier method. The ME voltage was recorded by varying the a.c magnetic field $\left(\mathrm{H}_{\mathrm{ac}}\right)$ with a frequency of $850 \mathrm{~Hz}$ at constant d.c. magnetic field $\left(\mathrm{H}_{\mathrm{dc}}\right.$ at1000 Oe). The variation of ME voltage is shown in Fig. 12 of the $\mathrm{Ba}_{1-y} \mathrm{Gd}_{y} \mathrm{Ti}_{1-x} \mathrm{Fe}_{x} \mathrm{O}_{3}(\mathrm{x}=0.05 ; \mathrm{y}=0.005,0.01$ and 0.015$)$ ceramics. A linear increasing trend of $a_{M E}$ with $\mathrm{H}_{d c}$ is obtained and $\mathrm{a}_{M E}$ is calculated with $\mathrm{H}_{\mathrm{ac}}$ using the following relation, $\alpha=\frac{\mathrm{dE}}{\mathrm{dH}}=\left(\frac{1}{\mathrm{t}}\right)\left(\frac{\mathrm{dV}}{\mathrm{dH}}\right)=\frac{\mathrm{V}_{\text {out }}}{\mathrm{ht}}$ Where, $\mathrm{V}_{\text {out }}-\mathrm{ME}$ voltage, $\mathrm{h}$-amplitude of $\mathrm{H}_{\mathrm{ac}} \mathrm{t}$-thickness of the sample.

Tesfakiros Woldu et al have already reported the detailed descriptions about ME measurement [3]. In TM doped BTO system, a high value of $\mathrm{a}_{\mathrm{ME}} 31.15 \mathrm{mV} / \mathrm{cm}$. Oe has been reported by Verma et. al., [8]. In Dy ${ }^{3+}$ $\mathrm{Fe}^{3+}$ co-substituted BTO ceramics, the ME coupling is originated from the magneto-crystalline anisotropy and microstrain [21]. The true ME coupling is originated from the magneto-crystalline anisotropy, superexchange interaction, and strain via magnetostriction [45]. $\mathrm{Fe}^{3+}-\mathrm{O}^{2-}-\mathrm{Fe}^{3+}$ super-exchange and $\mathrm{Gd}^{3+}-\mathrm{O}^{2-}$ $\mathrm{Gd}^{3+}$ interactions enhance the magnetisation as an increase of $\mathrm{Gd}$-concentration. On contrary to this, the $M E$ coupling coefficient $\left(a_{M E}\right)$ decreases up to $y=0.01$ then increases in $y=0.015$ ceramics. The large value of magneto-crystalline anisotropy depends on the $2 \mathrm{~b}$-site than the 12k-site [35]. Nevertheless, the absence of $2 b$-site in $y=0.015$ ceramics are due to the T-symmetry restricts the magneto-crystalline anisotropy and it is independent of the trend of $a_{M E}$. Thus, both super-exchange and magneto-crystalline anisotropy are excluded from the discussion of the ME effect.

The next feasibility is the strain driven ME coupling. The aforementioned discussions denote that the increase of Gd-concentration tries to maintain charge neutrality. This reduces the oxygen vacancies that lead to a decrease in microstrain, which assures the probability for the degradation of $a_{M E}$ in the samples with structural heterogeneity. While ME coupling is not feasible for the single T-phase ceramics due to the 
absence of bridging oxygen in the tetragonal unit cell is unable to permit the creation of oxygen vacancy than the hexagonal phase. Eventhough, the value of $a_{M E}$ in the single T-phase ceramics is increased which indicates the Gd-substitution is insufficient for the charge compensation that promotes oxygen vacancies. Cao. et. al., reported that the T-phase oxygen vacancy and Ti-vacancy induce the magnetic moment of $1.54 \mu_{\mathrm{B}}$ and $2.34 \mu_{\mathrm{B}}[46]$. The calculated strain $(\varepsilon)$ is listed in Table 1 , which gradually decreases up to $y=0.01$ ceramics and then increases in $y=0.015$ ceramics, suggests the linear relation between strain and ME coupling coefficient. To conclude this, the observed multiferroic feature is originated from the strain mediated ME coupling.

\section{Conclusion}

Phase pure $\mathrm{Ba}_{1-y} \mathrm{Gd}_{y} \mathrm{Ti}_{1-x} \mathrm{Fe}_{x} \mathrm{O}_{3}(x=0.05 ; \mathrm{y}=0.005,0.01$ and 0.015$)$ ceramics prepared by mixed oxide route. The influence of $\mathrm{Gd}^{3+}-\mathrm{Fe}^{3+}$ substitution on the structural, morphological, spectral, electrical, magnetic, and multiferroic properties investigated. An increase in the $\mathrm{Gd}^{3+}$ substitution amount promotes the structural transition from tetragonal $(\mathrm{P} 4 \mathrm{~mm})$ + hexagonal $\left(\mathrm{PG}_{3} / \mathrm{mmc}\right)$ to a single tetragonal phase with $\mathrm{P} 4 \mathrm{~mm}$ symmetry. The incorporation of $\mathrm{Gd}^{3+}$ directly affects the physical properties such as electric, magnetic, and multiferroic properties while reentrant ferroelectric tetragonal phase. The interactions between $\mathrm{Fe}^{3+}-\mathrm{Fe}^{3+}$ and $\mathrm{Gd}^{3+}-\mathrm{Gd}^{3+}$ act as the origins of ferromagnetism through the non-magnetic oxygen ion $\left(\mathrm{O}^{2-}\right)$. The rapid formation of T-phase due to $\mathrm{Gd}$-substitution is unable to improve the magnetoelectric property since the decrease of MD constant and ME coupling coefficient compared with the $y=0$ ceramics. The calculated strain values from the XRD data maintain the linear trend with the observed ME coupling coefficient that is the origin of magnetoelectric property.

\section{Declarations}

\section{Acknowledgements}

The author is grateful for the financial assistance of the University Grants Commission through the BSR fellowship (F.No.:25 - 1/2014-15(BSR)/7-305/2010/(BSR)). DST-FIST also acknowledged for Powder XRD facility in the Department of Physics, Manonmaniam Sundaranar University

\section{References}

1. Rahul MundiyaniyilThankachan B, Raneesh, AnshidaMayeen S, Karthika S, Vivek SS, Nair (2018) Sabu Thomas, and Nandakumar Kalarikkal, Room temperature magnetoelectric coupling effect in $\mathrm{CuFe}_{2} \mathrm{O}_{4}-\mathrm{BaTiO}_{3}$ core-shell and nanocomposites. J Alloy Compd 731:288-296

2. Shankar S, Kumar M, Tuli V, Thakur OP, Jayasimhadri M (2018) Energy storage and magnetoelectric coupling in ferroelectric-ferrite composites. J Mater Sci: Mater Electron 29 no:21: 18352-18357 
3. Tesfakiros Woldu B, Raneesh BK, Hazra S, Srinath P, Saravanan MVR, Reddy, Kalarikkal N (2017) A comparative study on structural, dielectric and multiferroic properties of $\mathrm{CaFe}_{2} \mathrm{O}_{4} / \mathrm{BaTiO}_{3}$ core-shell and mixed composites. J Alloy Compd 691:644-652

4. Lorenz M, Wagner G, Lazenka V, Schwinkendorf P, Modarresi H, Margriet J, Van Bael (2015) André Vantomme, Kristiaan Temst, Oliver Oeckler, and Marius Grundmann. Correlation of magnetoelectric coupling in multiferroic $\mathrm{BaTiO}_{3}-\mathrm{BiFeO}_{3}$ superlattices with oxygen vacancies and antiphase octahedral rotations. Appl Phys Lett 106 no(1):012905

5. Staruch M, Li JF, Wang Y, Viehland D, Finkel P (2014) Giant magnetoelectric effect in nonlinear Metglas/PIN-PMN-PT multiferroic heterostructure. Appl Phys Lett 105 no:15: 152902

6. Sterbinsky GE, Wessels BW, Kim J-W, Karapetrova E, Ryan PJ (2010) and D. J. Keavney. Strain-driven spin reorientation in magnetite/barium titanate heterostructures. Appl Phys Lett 96 no:9: 092510

7. Verma KC, Gupta V, Kaur J, Kotnala RK (2013) Raman spectra, photoluminescence, magnetism and magnetoelectric coupling in pure and $\mathrm{Fe}$ doped $\mathrm{BaTiO}_{3}$ nanostructures. J Alloys Compd 578:5-11

8. Verma KC, Kotnala RK (2016) Multiferroic approach for $\mathrm{Cr}, \mathrm{Mn}, \mathrm{Fe}, \mathrm{Co}, \mathrm{Ni}, \mathrm{Cu}$ substituted $\mathrm{BaTiO}_{3}$ nanoparticles. Materials Research Express 3 no:5: 055006

9. Samad R, Want B (2018) Improved magnetoelectric effect in ytterbium doped $\mathrm{BaTiO}_{3}-\mathrm{CoFe}_{2} \mathrm{O}_{4}$ particulate multiferroic composites. J Alloy Compd 755:89-99

10. Manish Kumar S, Shankar V, Tuli S, Mittal V, Joshi MK, Jha, Gupta G. Structural Analysis and Magnetoelectric Sensing in Cobalt Ferrite-BaTiO ${ }_{3}$ Composites. National Academy Science Letters 2020: $1-3$

11. Madhan K, Jagadeeshwaran C, Murugaraj R (2019) Enhancement of electrical and magnetic properties in acceptor-doped $\mathrm{BaTiO}_{3}$ ferroelectric ceramics. J Mater Sci: Mater Electron 30 no:3: 2953-2965

12. Jyoti, Shah, Ravinder K Kotnala. Induced magnetism and magnetoelectric coupling in ferroelectric $\mathrm{BaTiO}_{3}$ by $\mathrm{Cr}$-doping synthesized by a facile chemical route. Journal of Materials Chemistry A 1 , 2013, no. 30 2013: 8601-8608

13. Ganguly M, Rout SK, Sinha TP, Sharma SK, Park HY, Ahn CW (2013) and I. W. Kim. Characterization and rietveld refinement of A-site deficient lanthanum doped barium titanate. J Alloys Compd 579:473-484

14. Nadejda Horchidan L, Padurariu CE, Ciomaga L, Curecheriu M, Airimioaei F, Doroftei (2020) Florin Tufescu, and Liliana Mitoseriu. Room temperature phase superposition as origin of enhanced functional properties in $\mathrm{BaTiO}_{3}$-based ceramics. J Eur Ceram Soc 40 no(4):1258-1268

15. Cheng X, Shen M (2007) Enhanced spontaneous polarization in $\mathrm{Sr}$ and Ca co-doped $\mathrm{BaTiO}_{3}$ ceramics. Solid State Commun 141 no:11: 587-590

16. Lin F, Shi W (2009) Magnetic properties of transition-metal-codoped $\mathrm{BaTiO}_{3}$ systems. J Alloy Compd 475:64-69 
17. Soumya Rajan PMM, Gazzali, Chandrasekaran G (2016) Electrical and magnetic phase transition studies of $\mathrm{Fe}$ and $\mathrm{Mn}$ co-doped $\mathrm{BaTiO}_{3}$. J Alloy Compd 656:98-109

18. Lu D-Y, Liang Y (2018) Valence states and dielectric properties of fine-grained $\mathrm{BaTiO}_{3}$ ceramics codoped with double valence-variable europium and chromium. Ceram Int 44 no:12: 14717-14727

19. Kumar P, Kumar V (2018) Effect of co-substitution of $\mathrm{Sm}^{3+}$ and $\mathrm{Fe}^{3+}$ ions on structural and dielectric properties of $\mathrm{BaTiO}_{3}$ ceramics. J Alloy Compd 731:760-765

20. Sushrisangita Sahoo PK, Mahapatra RNP, Choudhary, Alagarsamy P (2018) Influence of compositional variation on structural, electrical and magnetic characteristics of $\left(\mathrm{Ba}_{1-\mathrm{x}} \mathrm{Gd}\right)\left(\mathrm{Ti}_{1-\mathrm{x}} \mathrm{Fe}_{\mathrm{x}}\right) \mathrm{O}_{3}$ $(0.2 \leq x \leq 0.5)$. Materials Research Express 5 no(1):016101

21. Rubavathi PE, Dhayanithi D, Giridharan NV, Rahul MT, Kalarikkal N, Sundarakannan B (2021 Jul) Origin of magnetic, magnetoelectric effect and the influence of reentrant ferroelectric phase on the structural and multiferroic properties of $\mathrm{Dy}^{3+}-\mathrm{Fe}^{3+}$ co-substituted $\mathrm{BaTiO}_{3}$ ceramics. J Magn Magn Mater 1:168260

22. Petricek V, Dusek M, Palatinus L. Jana2006. Structure determination software programs. Prague (Czech Republic): Institute of Physics, University of Prague (2006)

23. Esther Rubavathi P, Venkidu L, Veera Gajendra Babu M, Venkat Raman R, Bagyalakshmi B, Abdul Kader SM, Baskar K, Muneeswaran M, Giridharan NV, Sundarakannan B (2019) Structure, morphology and magnetodielectric investigations of $\mathrm{BaTi}_{1-\mathrm{x}} \mathrm{Fe}_{\mathrm{x}} \mathrm{O}_{3-\delta}$ ceramics. J Mater Sci: Mater Electron 30:no. 6: 5706-5717

24. Rubavathi PE, Benoy SM, Baskar K, Venkidu L, Veera Gajendra Babu M, Dhayanithi D, Giridharan NV, Sundarakannan $\mathrm{B}(2020)$ Impact of non-magnetic $\mathrm{BaTiO}_{3}$ substitution on structure, magnetic, thermal and ferroelectric properties of $\mathrm{BiFeO}_{3}$ ceramics at morphotropic phase boundary. Mater Chem Phys 255:123560

25. Wondratschek, Hans, Ulrich Müller, and Union internationale de cristallographie. International tables for crystallography. Kluwer Academic, 2004, 283-284, 599-601

26. Y. C. Lin, Xian-Yang Wu, Xiao-Min Chen, Jian Chen, Dong-Xu Wen, Jin-Long Zhang, and Lei-Ting Li. EBSD study of a hot deformed nickel-based superalloy. Journal of alloys and compounds, 2015, 640: 101-113.

27. Dan Jia, Wenru Sun, Dongsheng Xu, and Fang Liu. Dynamic recrystallization behavior of GH4169G alloy during hot compressive deformation. Journal of Materials Science \& Technology, 2019, 35, no. 9: 1851-1859.

28. Jill Chastain, Handbook of X-ray photoelectron spectroscopy. Perkin-Elmer Corporation 1992, 40: 221.

29. B. C. Keswani, R. S. Devan, R. C. Kambale, A. R. James, Sandeep Manandhar, Y. D. Kolekar, and C. V. Ramana. Correlation between structural, magnetic and ferroelectric properties of Fe-doped (BaCa)TiO3 lead-free piezoelectric. Journal of Alloys and Compounds, 2017, 712: 320-333. 
30. Cai-Xia Li, Bin Yang, Shan-Tao Zhang, Dan-Qing Liu, Rui Zhang, Ye Sun, and Wen-Wu Cao. Effects of $\mathrm{Mn}$ doping on multiferroic and magnetocapacitive properties of $0.33 \mathrm{Ba} 0.70 \mathrm{Ca} 0.30 \mathrm{TiO}-0.67 \mathrm{BiFeO} 3$ diphasic ceramics. Journal of alloys and compounds, 2014, 590: 346-354.

31. Gang Er, Shingo Ishida, and Nobuyuki Takeuchi. Investigations of the electrical property, diffuse reflectance and ESR spectra of the La-(Fe, Mn)-codoped PTCR BaTiO3 annealed in reducing atmosphere. Journal of materials science, 1999, 34, no. 17: 4265-4270.

32. Taras Kolodiazhnyi, and Anthony Petric. Analysis of point defects in polycrystalline BaTiO3 by electron paramagnetic resonance. Journal of Physics and Chemistry of Solids, 2003, 64, no. 6: 953960.

33. T. R. N. Kutty, and P. Murugaraj. EPR study on the role of Mn in enhancing PTC of BaTiO3. Materials Letters, 1985, 3, no. 5-6: 195-199.

34. The-Long Phan, P. Zhang, D. Grinting, S. C. Yu, N. X. Nghia, N. V. Dang, and V. D. Lam. Influences of annealing temperature on structural characterization and magnetic properties of $\mathrm{Mn}$-doped $\mathrm{BaTiO} 3$ ceramics. Journal of Applied Physics, 2012, 112, no. 1: 013909.

35. Deepam Maurya, Harikishan Thota, Ashish Garg, Brajesh Pandey, Prem Chand, and H. C. Verma. Magnetic studies of multiferroic $\mathrm{Bi} 1-\mathrm{xSmxFeO} 3$ ceramics synthesized by mechanical activation assisted processes. Journal of Physics: Condensed matter, 2008, 21, no. 2: 026007.

36. You Xu, Gui-Ling Yang, Da-Ping Chu, and Hong-Ru Zhai. Theory of the single ion magnetocrystalline anisotropy of $3 d$ ions. physica status solidi (b), 1990, 157, no. 2: 685-693.

37. A. Mukherjee, S. Basu, P. K. Manna, S. M. Yusuf, and M. Pal. Enhancement of multiferroic properties of nanocrystalline BiFeO3 powder by Gd-doping. Journal of Alloys and Compounds, 2014, 598: 142150.

38. Yu-Ran Luo, and J. A. Kerr. Bond dissociation energies. CRC Handbook of Chemistry and Physics, 2012, 89: 89.

39. P. Esther Rubavathi, M. Veera Gajendra Babu, B. Bagyalakshmi, L. Venkidu, D. Dhayanithi, N. V. Giridharan, and B. Sundarakannan. Impact of $\mathrm{Ba} / \mathrm{Ti}$ ratio on the magnetic properties of $\mathrm{BaTiO} 3$ ceramics. Vacuum, 2019, 159: 374-378.

40. R. V. K. Mangalam, Mahuya Chakrabrati, D. Sanyal, A. Chakrabati, and A. Sundaresan. Identifying defects in multiferroic nanocrystalline $\mathrm{BaTiO} 3$ by positron annihilation techniques. Journal of Physics: Condensed Matter, 2009, 21, no. 44: 445902.

41. The-Long Phan, P. Zhang, D. S. Yang, T. D. Thanh, D. A. Tuan, and S. C. Yu. Origin of ferromagnetism in BaTiO3 nanoparticles prepared by mechanical milling. Journal of Applied Physics, 2013, 113, no. 17: 17 E305.

42. A. Sundaresan, R. Bhargavi, N. Rangarajan, U. Siddesh, and C. N. R. Rao. Ferromagnetism as a universal feature of nanoparticles of the otherwise nonmagnetic oxides. Physical Review B, 2006, 74, no. 16: 161306.

43. G. Alvarez, A. Conde-Gallardo, H. Montiel, and R. Zamorano. About room temperature ferromagnetic behavior in BaTiO3 perovskite. Journal of Magnetism and Magnetic Materials, 2016, 401: 196-199. 
44. Pittala Suresh, and S. Srinath. Study of structure and magnetic properties of rare earth doped BiFe03. Physica B: Condensed Matter, 2014, 448: 281-284.

45. Hyun M. Jang, Jung H. Park, Sangwoo Ryu, and $S$. R. Shannigrahi. Magnetoelectric coupling susceptibility from magnetodielectric effect. Applied Physics Letters, 2008, 93, no. 25: 252904.

46. G. A. Gehring, On the microscopic theory of the magnetoelectric effect. Ferroelectrics, 1994, 161, no. 1: $275-285$.

47. D. Cao, M. Q. Cai, Yue Zheng, and W. Y. Hu. First-principles study for vacancy-induced magnetism in nonmagnetic ferroelectric BaTiO3. Physical Chemistry Chemical Physics, 2009, 11, no. 46: 1093410938.

\section{Figures}

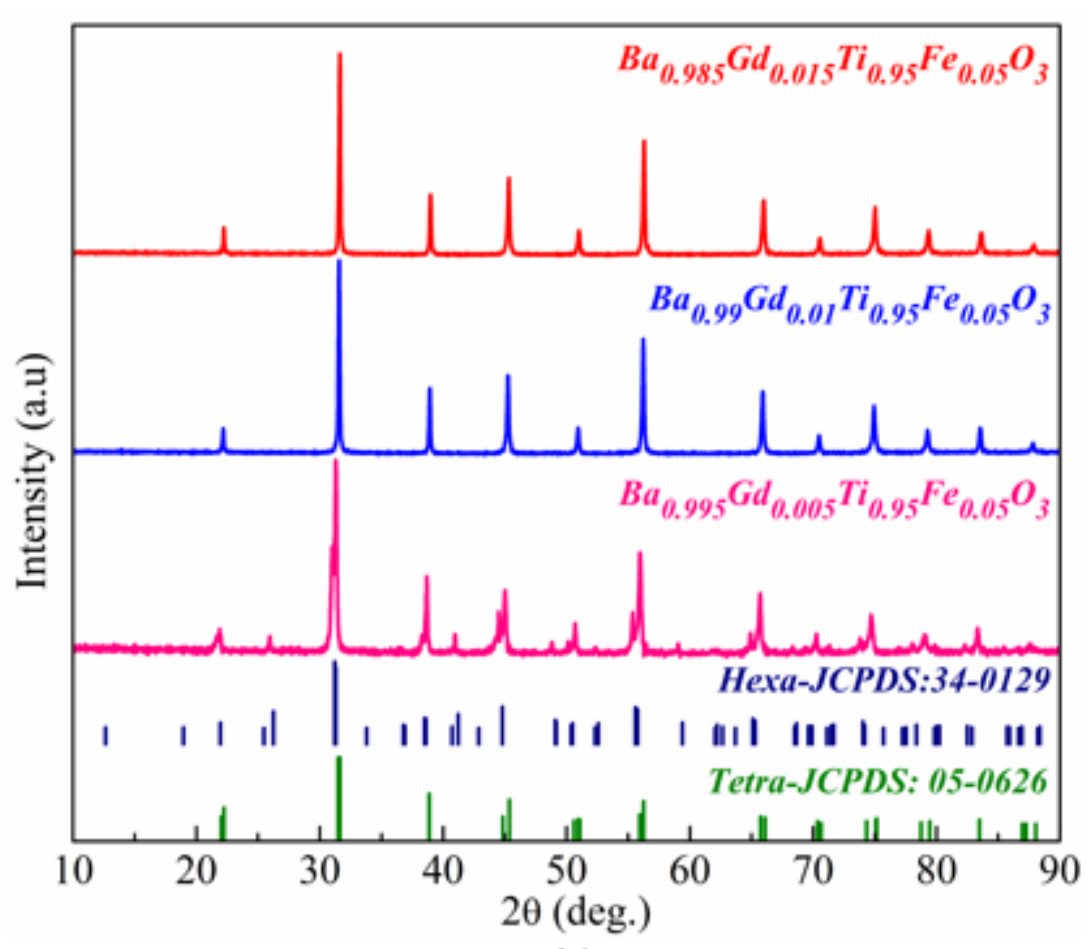

(a)
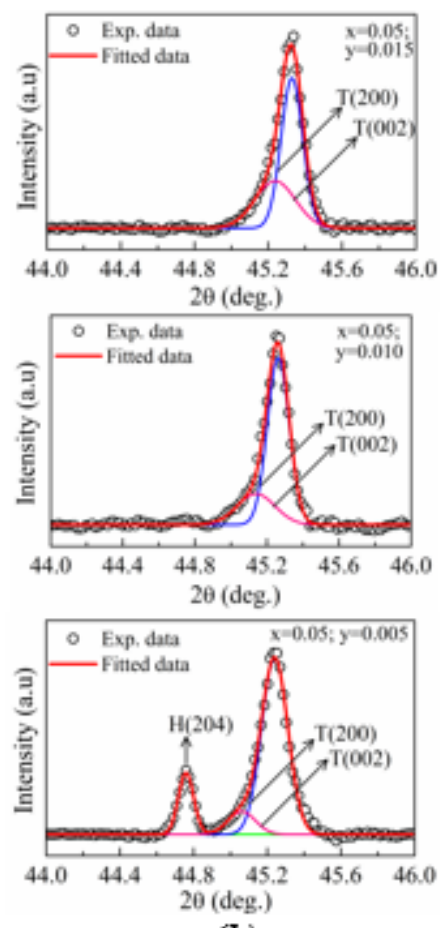

(b)

\section{Figure 1}

(a) PXRD patterns of the Ba1-yGdyTi1-xFexO3 $(x=0.05 ; y=0.005,0.01$ and 0.015$)$ ceramics (b) Enlarged view of XRD patterns in the vicinity of $44-460$ of Ba1-yGdyTi1-xFexO3 $x=0.05 ; y=0,0.005,0.01$ and 0.015 ceramics 

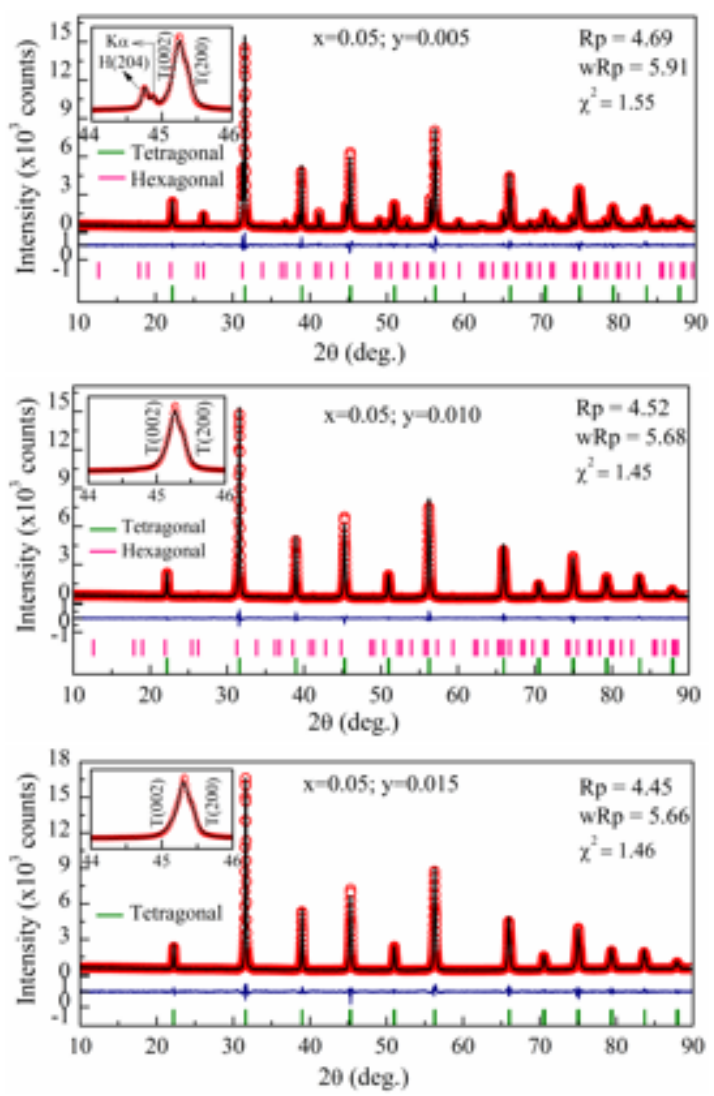

Figure 2

Rietveld refined PXRD patterns of the Ba1-yGdyTi1-xFexO3 ( $x=0.05 ; y=0.005,0.01$ and 0.015$)$ ceramics
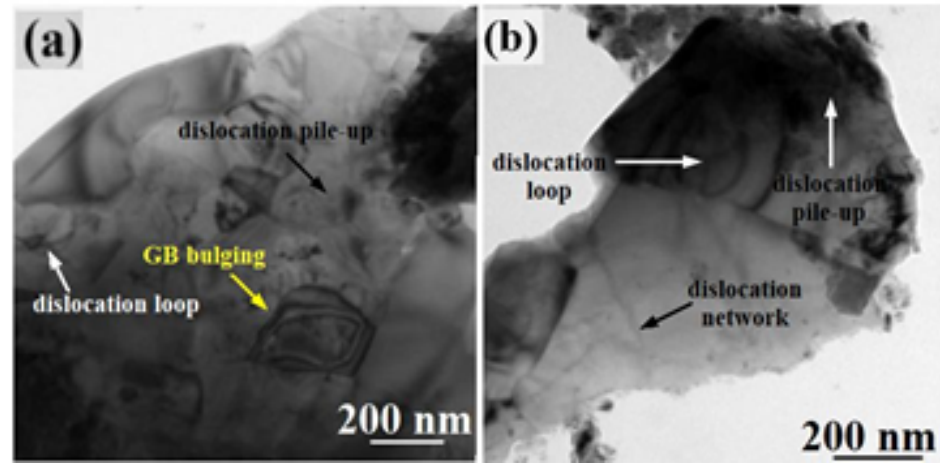

(c)

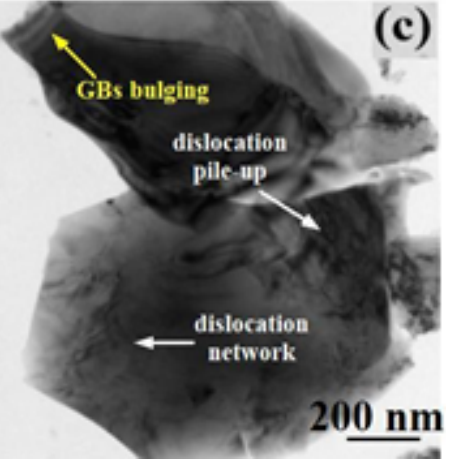

Figure 3

(a-c) Bright field micrographs of the Ba1-yGdyTi1-xFex03; $x=0.05 ; y=, 0.005$ (a), 0.01 (b) and 0.015 (c) ceramics 


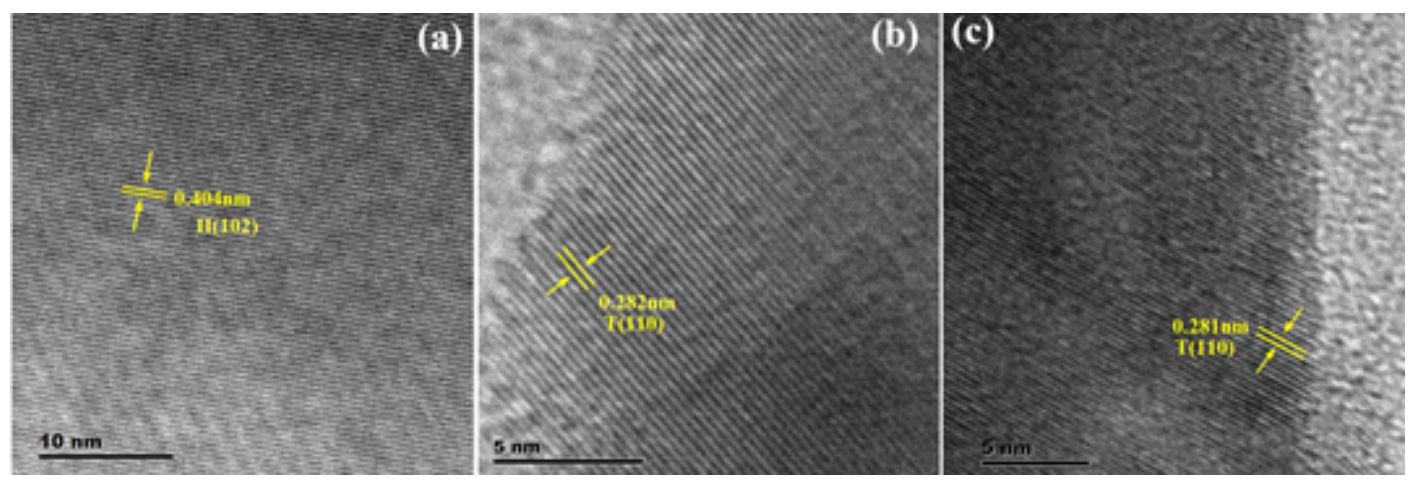

\section{Figure 4}

(a-c) HREM fringes of the Ba1-yGdyTi1-xFexO3; $x=0.05 ; y=0.005$ (a), 0.01 (b) and 0.015 (c) ceramics

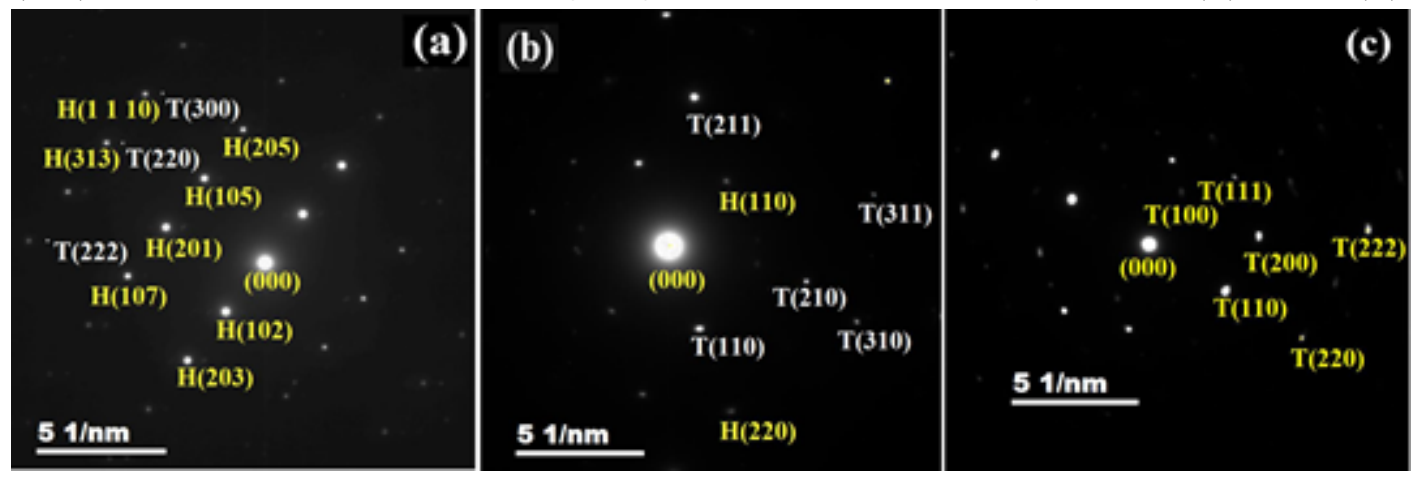

Figure 5

(a-c) SAED patterns of the Ba1-yGdyTi1-xFexO3; $x=0.05 ; y=0.005$ (a), 0.01 (b) and 0.015 (c) ceramics 

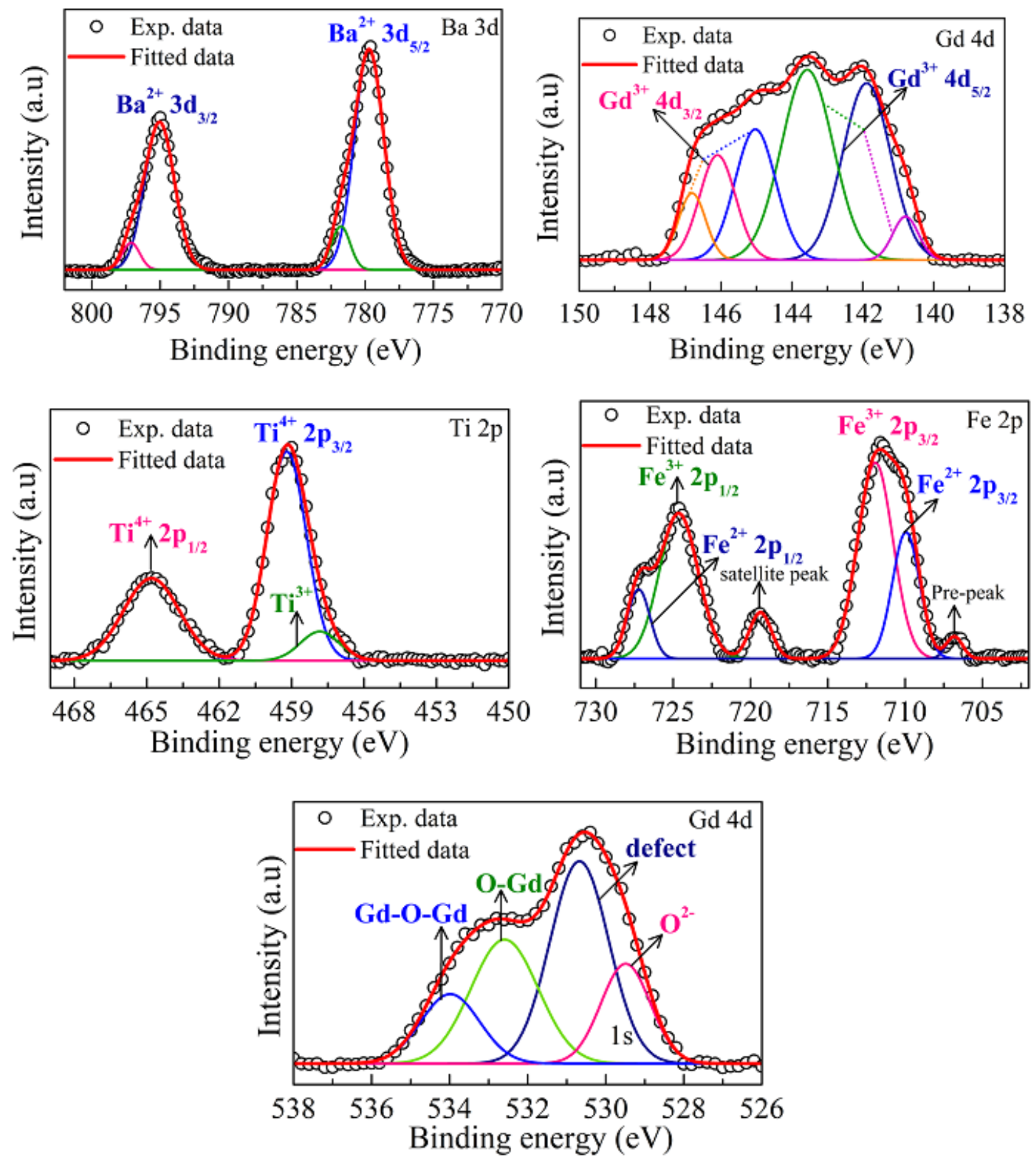

Figure 6

XPS core-level spectra of $\mathrm{Ba}(3 \mathrm{~d}), \mathrm{Gd}(4 \mathrm{~d}), \mathrm{Ti}(2 \mathrm{p}), \mathrm{Fe}(2 \mathrm{p})$ and $\mathrm{O}(1 \mathrm{~s})$ in the Ba0.995Gd0.005Ti0.95Fe0.0503 ceramics 


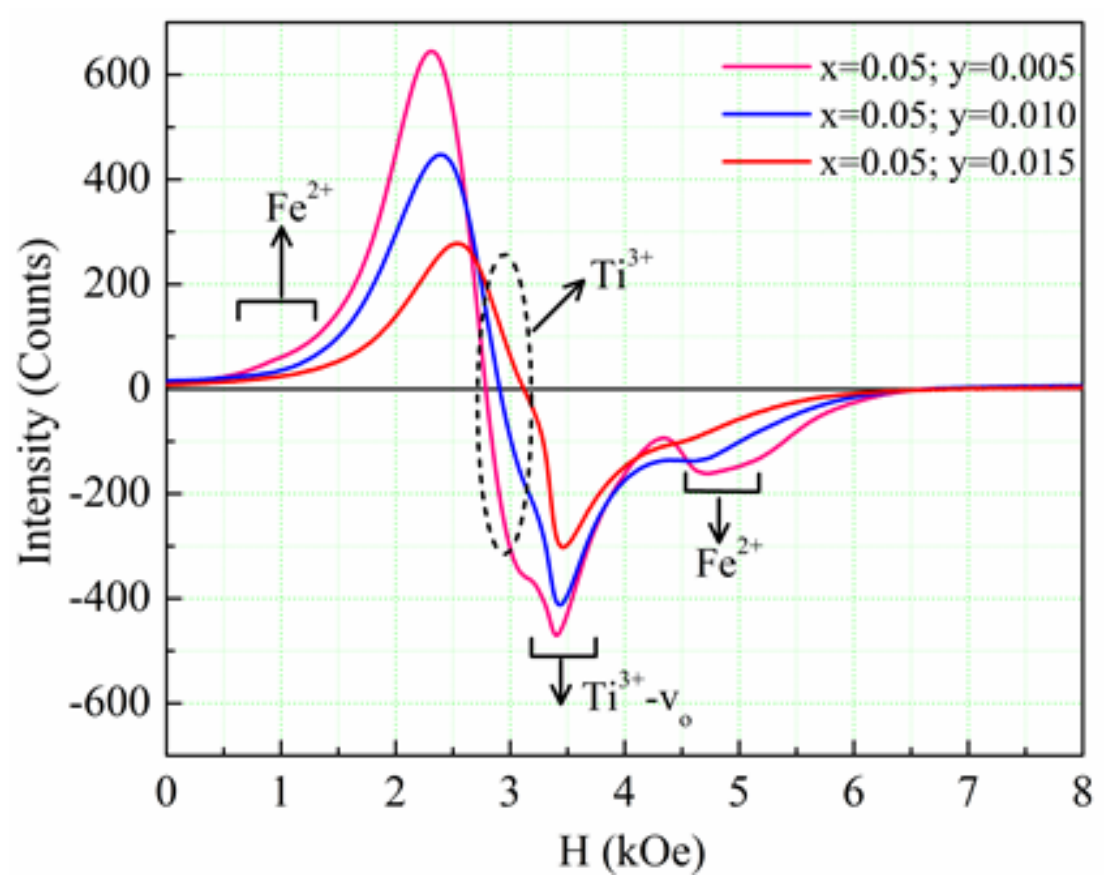

Figure 7

EPR spectra of the Ba1-yGdyTi1-xFexO3 $(x=0.05 ; y=0.005,0.01$ and 0.015$)$ ceramics
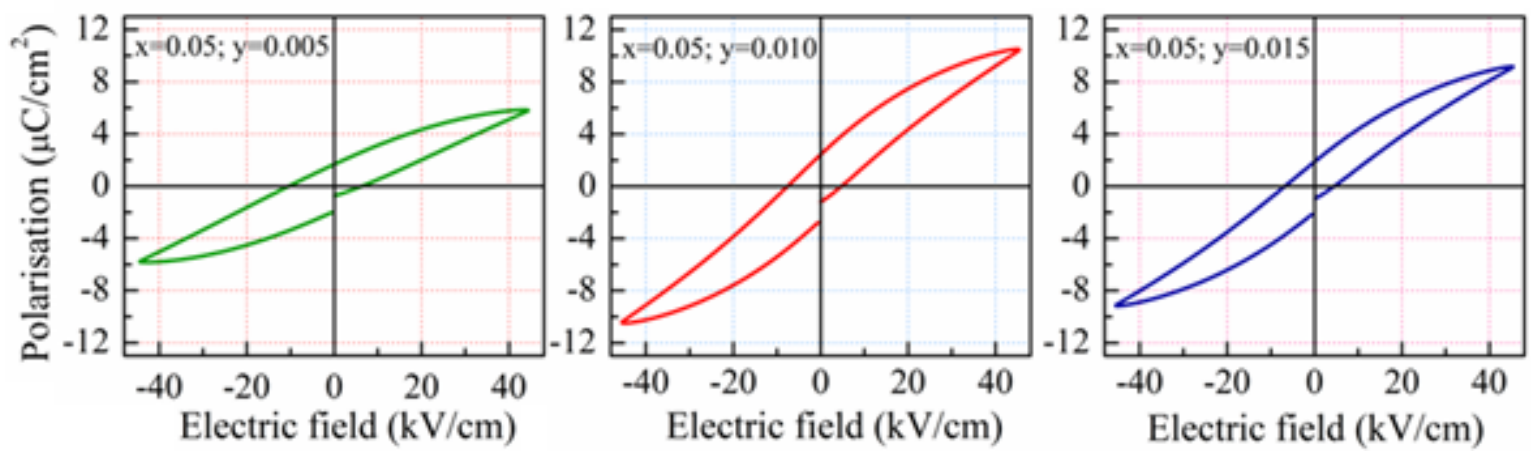

Figure 8

(a-c) P-E hysteresis loops of the Ba1-yGdyTi1-xFexO3 $(x=0.05 ; y=0.005,0.01$ and 0.015$)$ ceramics
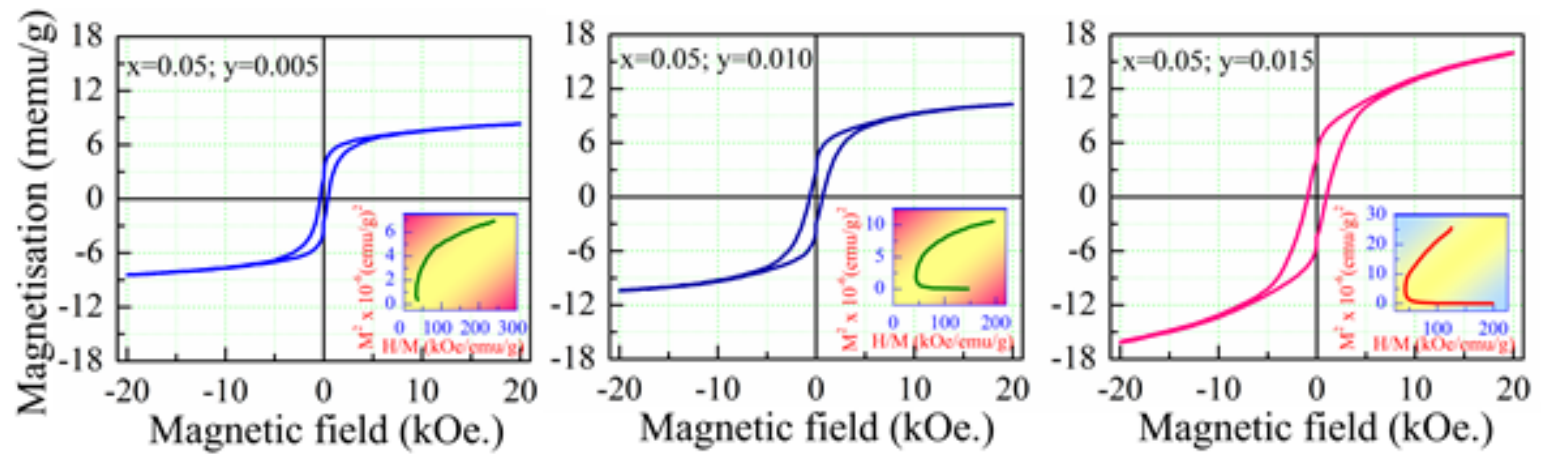

Figure 9 
(a-c) $\mathrm{M}-\mathrm{H}$ hysteresis loops and the inserts corresponding to ABK plot for the Ba1-yGdyTi1-xFexO3; $x=0.05$; $y=0.005,0.01$ and 0.015 ) ceramics
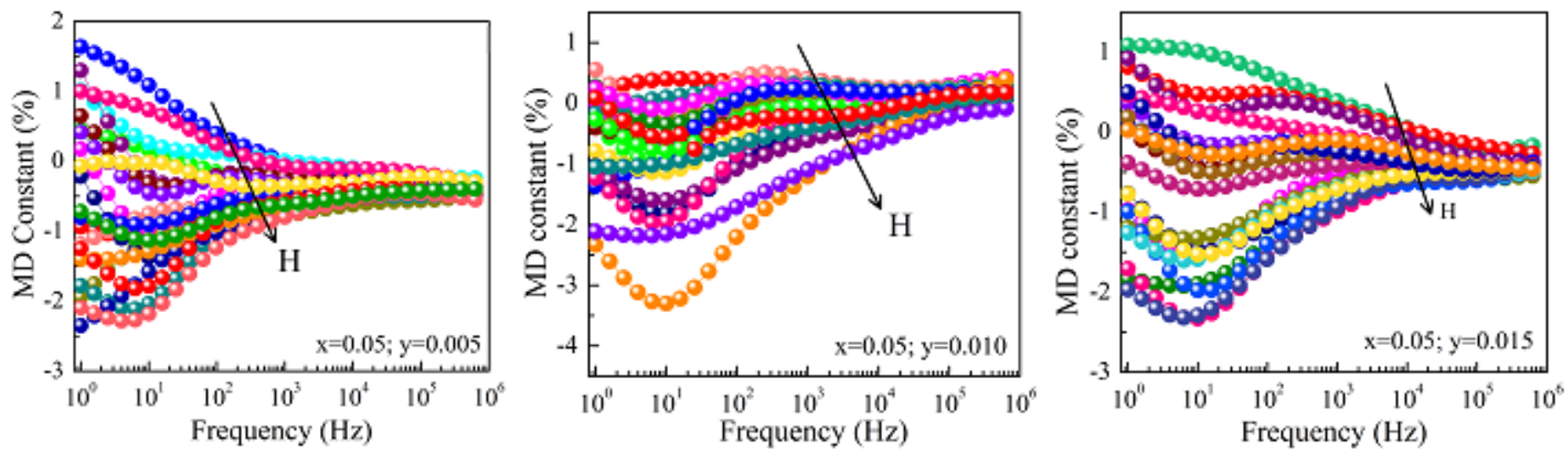

Figure 10

(a-c) Magnetodielectric constant as a function of frequency for the Ba1-yGdyTi1-xFexO3; $x=0.05 ; y=0.005$, 0.01 and 0.015 ) ceramics
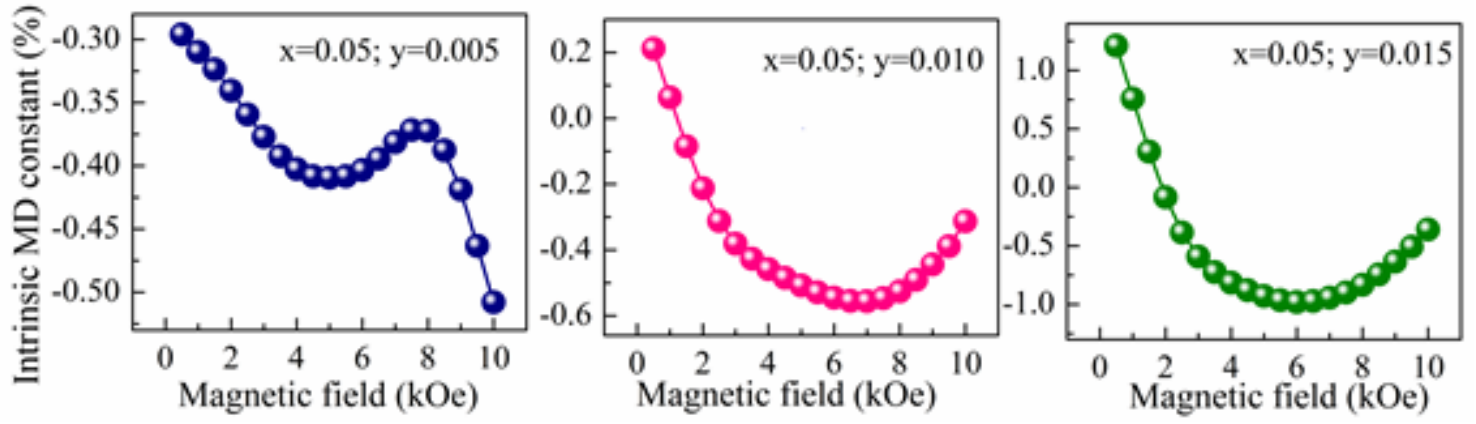

Figure 11

(a-c) Intrinsic magnetodielectric constant as a function of magnetic field for the Ba1-yGdyTi1-xFexO3; $x=0.05 ; y=0.005,0.01$ and 0.015$)$ ceramics 


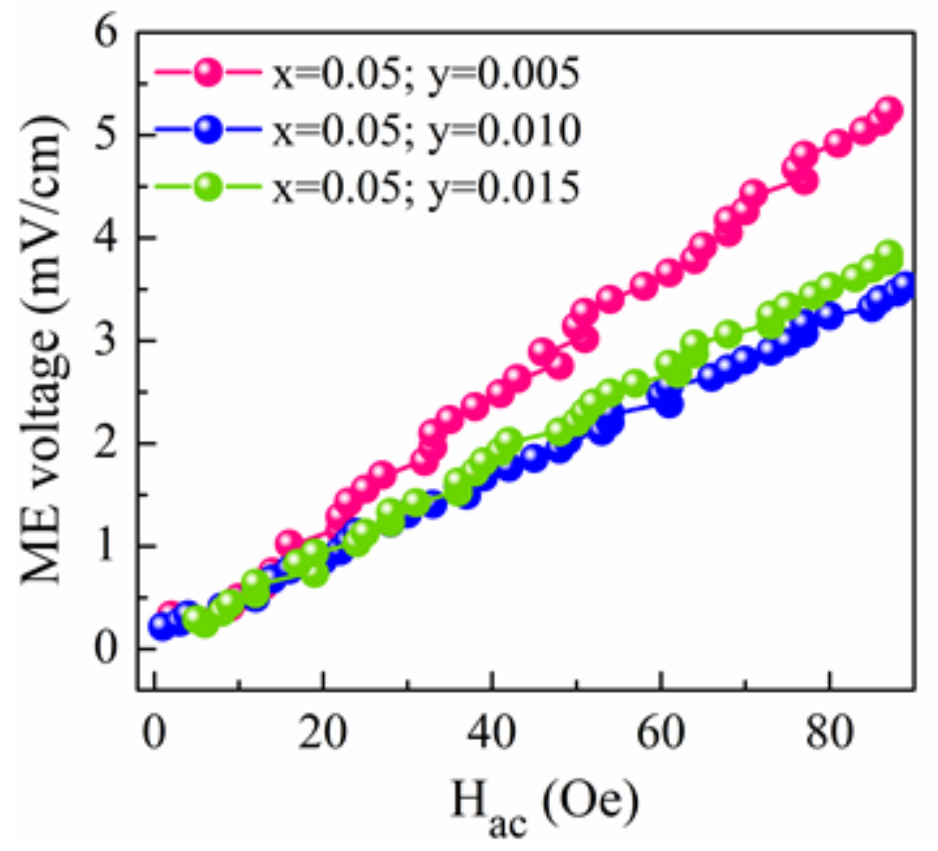

Figure 12

Magnetoelectric (ME) voltage as a function of a.c. magnetic field for the Ba1-yGdyTi1-xFexO3; $x=0.05$; $y=0.005,0.01$ and 0.015$)$ ceramics 